\title{
Modelagem em um ambiente virtual de aprendizagem inclusivo: uso de mapas conceituais
}

\author{
Modeling in a inclusive learning management system: \\ the use of conceptual maps
}

Marilia Abrahão Amaral, Silvia Regina P. Quevedo

Ambientes Virtuais de Aprendizagem, mapa conceitual, Moodle

Learning Management System, conceptual map, Moodle
Os Ambientes Virtuais de Aprendizagem (AVAs) estão modificando as antigas formas de ensinar e aprender porém, não privilegiam a educação para todos e sem barreiras. Com o intuito de contribuir com a Educação a Distância (EAD) inclusiva, este artigo aborda a aprendizagem do deficiente visual, delimita seu perfil e apresenta as modificações realizadas na plataforma Moodle. A metodologia utilizada para este trabalho foi a revisão bibliográfica, que concentrou sua busca a partir da criação de um modelo contextual, baseado em mapas conceituais, para a definição do perfil do usuário deficiente visual, considerando suas características, necessidades e expectativas. Posteriormente foram definidos os mapas do domínio de conhecimento e proposto o modelo de adaptação do conteúdo inclusivo. No prosseguimento, foi desenvolvida pesquisa aplicada na plataforma Moodle, visando apoiar o processo de ensino-aprendizagem para os deficientes visuais.

The Learning Management Systems are changing the old ways of teaching and learning but do not emphasize education for all and without barriers. Aiming to contribute to distance learning inclusive, this article discusses the learning of visually impaired defines your profile and presents the modifications to the Moodle platform. The methodology used for this study was a literature review, which focused the search from the creation of a contextual model, based on conceptual maps, to define the user profile visually impaired, considering their characteristics, needs and expectations. Later maps were defined knowledge domain and proposed the model of adaptation of content inclusive. In pursuit, was developed applied research in the Moodle platform, to support the process of teaching and learning for the visually impaired.

\section{Introdução}

O avanço das Tecnologias de Informação e Comunicação (TIC) contribuíram para a expansão da Educação a Distância - EaD, que foi inicialmente configurada em materiais impressos, TV e rádio, e agora conta com e-learning (cursos a distância on-line) e m-learning (e-learning realizado através de dispositivos móveis) (TAROUCO 
ET.AL, 2004). As possibilidades que essas modalidades (e-learning e m-learning) proporcionam tornam o ensino a distância mais eficiente. Além disso, estudos referentes à interface e teorias pedagógicas aplicadas a ambientes informatizados vêm crescendo, contribuindo para a melhoria da qualidade da aprendizagem.

Porém, o que ainda se vê, muitas vezes, é um ambiente de aprendizagem informatizado desenvolvido para um determinado público alvo. Na tentativa de construir ambientes virtuais de aprendizagem que possam ser utilizados por um maior número de pessoas é que surge, o projeto WEBGD Acessível, que se pauta na apresentação de conteúdos sob a forma de objetos de aprendizagem, por suas características de reusabilidade e de adaptação.

O projeto está alinhado com as políticas de inclusão digital e social que expandem os direitos dos cidadãos à educação e tem como meta principal o desenvolvimento de um Ambiente Virtual de Ensino Aprendizagem (AVEA) inclusivo. O ambiente previsto, além de focar no público alvo usuários sem deficiência prevê a inclusão de pessoas com deficiência visual e auditiva.

Este ambiente inclusivo deve oferecer suporte a situações que primem pela compreensão do outro, e a percepção de formas de interdependência, respeitando os valores do pluralismo e a compreensão mútua. De forma a facilitar a construção do ambiente, utilizar-se-á de recursos adaptativos uma vez que permitem acesso personalizado de maneira automática às informações hipermídiáticas.

Para tanto é necessário personalizar o ambiente de acordo com as características, motivações, preferências e metas do aprendiz. Assim é necessário modelar o perfil do aprendiz. Com relação ao conteúdo a estruturação dos links ou sua apresentação podem ser diferentes para cada grupo de usuário, considerando suas características e necessidades.

O conteúdo das páginas e sua apresentação também devem ser diferenciados (AMARAL, 2008). Este artigo aborda a modelagem destes dois tópicos através de mapas conceituais e tem como questão norteadora verificar se os mapas conceituais são ferramentas capazes de modelar domínio do conhecimento e perfil de usuários.

\section{Mapas conceituais}

Segundo Souza (1999), mapas conceituais são utilizados como meio de comunicação para referenciar e descrever conceitos e suas respectivas relações. Assim como os textos, mapas conceituais podem transmitir informações, com a vantagem de proporcionar aos leitores a elaboração mais rápida de relações entre os conceitos, que dispostos graficamente, facilitam a construção de inferências (ROBINSON E KIEWRA, 1995).

Para elaborar um mapa conceitual, Moreira (1997) sugere que sejam identificados os conceitos-chave do conteúdo estudado, 
posicionando-os de forma que os mais inclusivos fiquem no topo do mapa, agregando os demais até completar o diagrama. Normalmente, para representar os conceitos utilizam-se figuras geométricas (retângulos, elipses, círculos) a fim de identificá-los como os nodos do mapa.

Para conectar os nodos, explicitando dessa forma a relação entre os conceitos, são utilizadas linhas, também intituladas como arcos.

Uma ou duas palavras-chave devem ser escritas acima do arco, com a finalidade de identificar a natureza da relação proposta, como mostra a Figura 1. Os dois conceitos conectados, somados ao significado do arco, formam uma proposição.

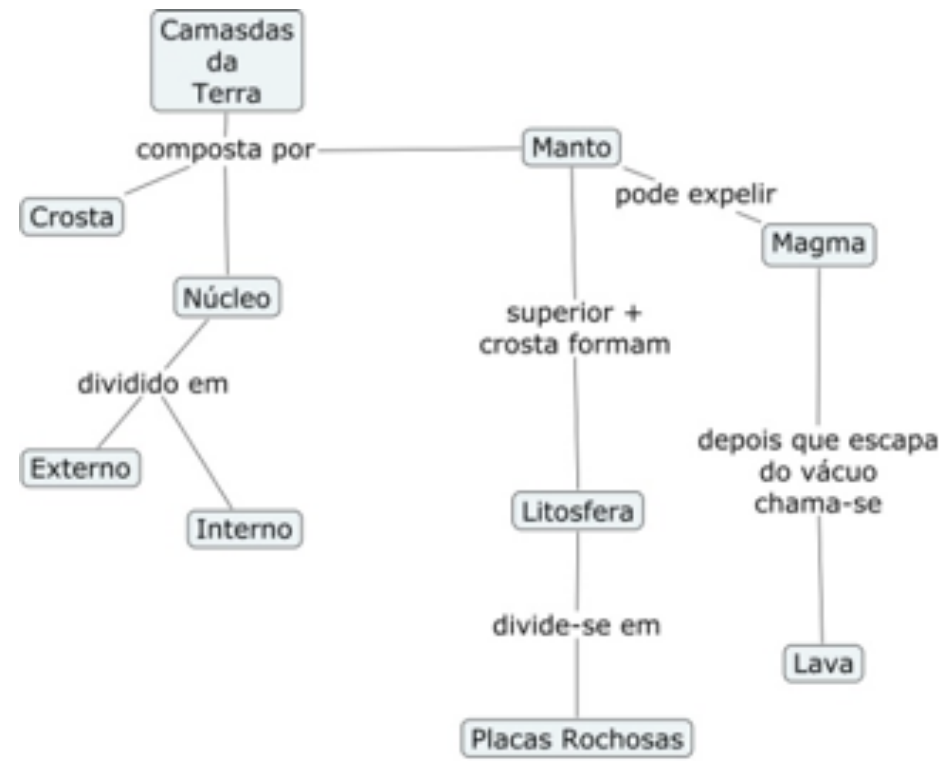

Figura 1 Mapa Conceitual (Fonte: Barros e Paulino, 2006)

Deste modo, pode-se afirmar que a utilidade dos mapas conceituais é bastante abrangente, sendo possível usá-los para traçar o roteiro de uma aula, de uma unidade de ensino ou até mesmo de um planejamento educacional completo. Os mapas podem se tornar um importante mecanismo para atentar o educador quanto à distinção e priorização dos conteúdos que se espera que sejam aprendidos (MOREIRA, 1997).

\section{Aprendizagem significativa}

Aprendizagem significativa é um conceito enfatizado por David Ausubel $(1963,1968,1978)$ desde a década de 1960. Nessa época, a influência behaviorista na educação era fortemente adotada o que levava o ensino e a aprendizagem a serem encarados como estímulos, repostas e reforços e não como significados. 
Entretanto, Ausubel (1978) insistia com uma "teoria da aprendizagem significativa" e acreditava que durante a aprendizagem significativa o significado lógico do material de aprendizagem se transforma em significado psicológico para o aprendiz.

Para Ausubel (1978), aprendizagem significativa é um processo por meio do qual uma nova informação se relaciona, de maneira substantiva (não literal) e não arbitrária, a um aspecto relevante da estrutura cognitiva do indivíduo. Isto é, nesse processo a nova informação interage com uma estrutura de conhecimento específica, existente na estrutura cognitiva de quem aprende.

Pode-se dizer, então que a aprendizagem significativa ocorre quando a nova informação relaciona-se com conhecimentos especificamente relevantes preexistentes na estrutura cognitiva. Existe, portanto, um processo de interação no qual conceitos mais relevantes e inclusivos interagem com a nova informação, servindo de ancoradouro, incorporando-o e assimilando-o; porém, ao mesmo tempo, modificando-se em função dessa ancoragem.

Mais tarde, Joseph Novak $(1996,1981,1984)$ iniciou sua colaboração com Ausubel $(1963,1968,1978)$ e refinou a divulgação desta teoria inserindo uma conotação humanista, além da técnica do mapeamento conceitual (NOVAK E GOWIN, 1984), (NOVAK E GOWIN, 1996); (MOREIRA E BUCHWEITZ, 1987), (MOREIRA E BUCHWEITZ, 1993)uma estratégia facilitadora da aprendizagem significativa.

De acordo com Novak (1996, P. 47), "a aprendizagem significativa subjaz à integração construtiva entre pensamento, sentimento e ação, que conduz ao engrandecimento humano". Ainda para Novak (1996), qualquer evento educativo é, uma ação para trocar significados (pensar) e sentimentos entre o aprendiz e o professor.

Por ser uma técnica flexível, o mapeamento conceitual, pode ser usado em diversas situações, para diferentes finalidades: instrumento de análise do currículo, técnica didática, recurso de aprendizagem, meio de avaliação (MOREIRA E BUCHWEITZ, 1993).

\section{Modelagem do ava inclusivo}

Modelar um AVA Inclusivo não é uma tarefa simples, levando-se em consideração a amplitude e as dificuldades peculiares que a forma de tratamento do conteúdo sugerido apresenta. Em vista disso, quando se decide criar um ambiente com tais características, é fundamental estreitar o vínculo com o público alvo, para que em parceria com o grupo desenvolvedor possam ser identificadas as necessidades e principais expectativas que eles apresentam.

O uso de mapas conceituais no processo de desenvolvimento do AVA Inclusivo pode ser inserido na fase de planificação, que consiste em projetar a aplicação, ou seja, modelar o ambiente. Nesta pesquisa os mapas conceituais foram utilizados para realizar a modelagem do usuário que será detalhada nesta seção. 


\subsection{Modelo do usuário}

Um modelo de usuário é constituído de descrições que são consideradas relevantes sobre o atual conhecimento e/ou atitudes do usuário, provendo informação ao ambiente para que ele adapte ao usuário individual. Modelagem do usuário é um processo que cobre todo o ciclo de vida de um modelo de usuário, incluindo aquisição de conhecimento sobre o usuário, construção, atualização, manutenção e exploração do modelo do usuário (КОСН, 2001).

Este modelo deve possuir toda informação que o sistema precisa saber sobre o usuário, ou seja, ele representa as características que formam o perfil do usuário, mantendo informações atualizadas sobre cada usuário. Inicialmente, temos o conhecimento que o ambiente deve atender os usuários sem deficiência e com deficiência auditiva ou visual.

Nesse estágio foram levantados alguns dados com o objetivo de identificar as características / atributos dos usuários, as tarefas e/ou ações a serem realizadas durante a interação, dificuldades e o nível de experiência em navegar pela Web. Com o intuito de trabalhar o aspecto inclusivo do AVA serão detalhados os mapas conceituais das características de usuários com deficiência visual e o modelo de usuário.

\subsubsection{Pessoas com deficiência visual/cegos}

De acordo com o Instituto Benjamin Constant, centro de referência nacional na área, a deficiência visual é uma categoria que inclui pessoas cegas e pessoas com visão reduzida. Conforme Regina Lázaro (2010), chefe da Divisão de Pesquisa, Documentação e Informação do Instituto Benjamin Constant, é considerado cego aquele que apresenta desde ausência total de visão até a perda da percepção luminosa e, indivíduo com baixa visão, o que apresenta desde a capacidade de perceber luminosidade até o grau em que a deficiência visual interfira ou limite seu desempenho.

Com relação ao acesso a ambientes virtuais de aprendizagem, é fato que a principal barreira, de acordo com Nielsen (2000), é encontrada pelos usuários que possuem deficiências visuais, já que a maioria das páginas web é altamente visual. Neste grupo estão incluídos os cegos, as pessoas com baixa visão e os daltônicos.

Estas pessoas possuem dificuldades em identificar imagens, mapas, links e animações, com o uso de cores, tamanho de fontes, navegação, tabelas de dados e preenchimento de formulários; necessitam de texto equivalente descritor da imagem apresentada na tela, e na maioria das vezes utilizam o teclado ao invés do mouse.

A descrição de imagens para estes usuários é um recurso muito forte de acesso, conforme descrito nas entrevistas realizadas por Santos (2006) ao declarar que o aluno cego se opõe ao entendimento 
de um desenho pela percepção tátil, preferindo a abstração decorrente de um texto explicativo. Em outra entrevista citada por este autor, o entrevistado afirma que às vezes o visual atrapalha e confunde, porque o visual é uma forma de juízo imediato e nem sempre é correto.

A dificuldade dos usuários cegos no acesso à internet é centralizada na visualização de textos e imagens, incluindo fotos, filmes, animações, tabelas e também à entrada de dados em preenchimento de formulários que é realizada via teclado. O material impresso é acessado em Braille. Estes usuários não podem ler as legendas, e às vezes usam displays em Braille acoplados. Utilizam leitores de tela e sintetizadores de voz (w3c, 2006). A Figura 2 resume as características dos usuários com deficiência visual, específicamente os cegos, as barreiras de acesso relacionadas com as possíveis tecnologias utilizadas para acesso ao conteúdo digital.

Para estes alunos a disponibilização de material on-line se torna interessante por facilitar o uso de tecnologia assistiva e permitir variação de mídia para prover mecanismos alternativos e facilitar o acesso (BURGSTAHLER, 2000). Os recursos textuais são utilizados em acesso de e-mails, chats ou grupos de discussão.

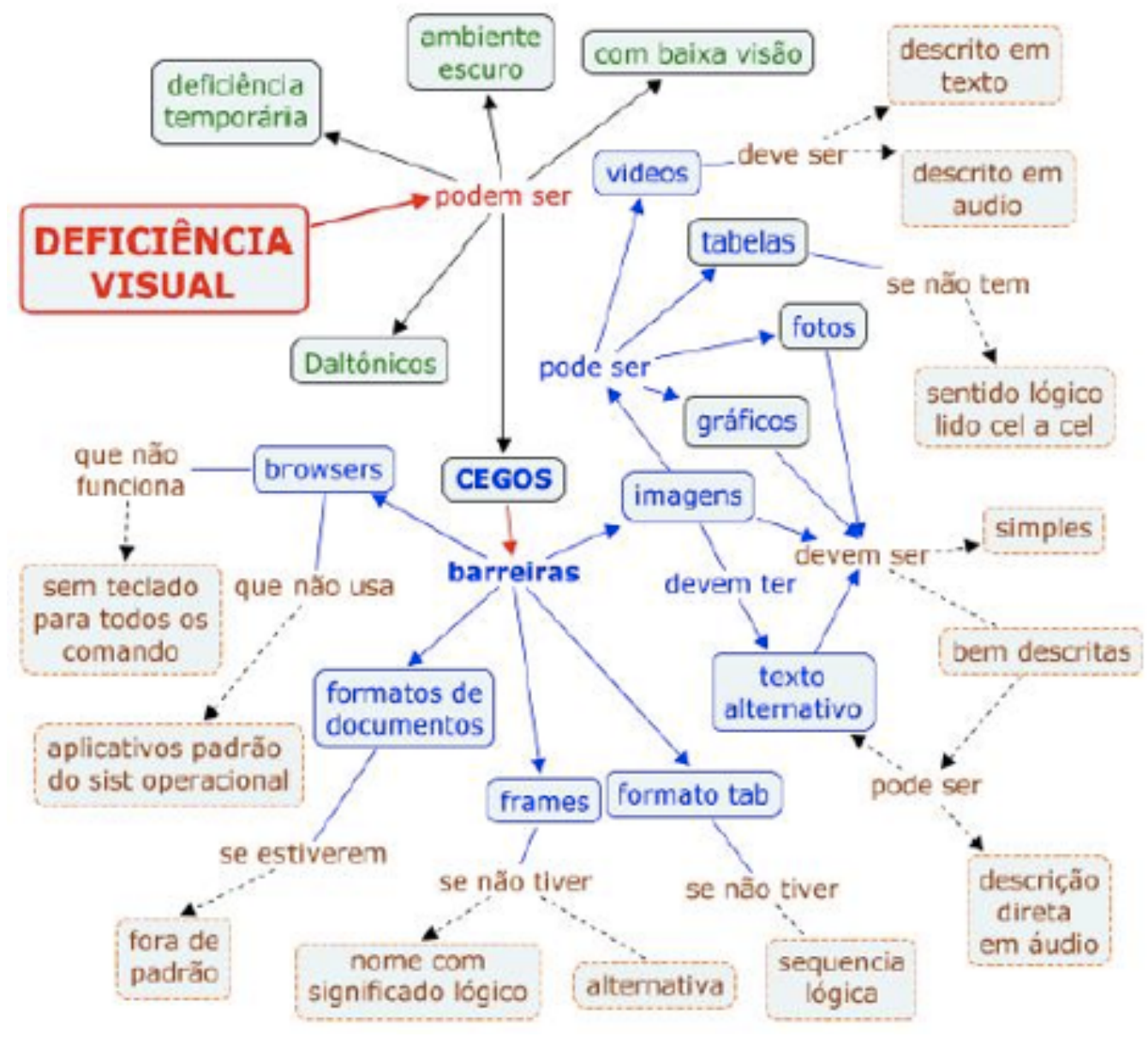

Figura 2 Usuários cegos e barreiras de acesso ao conteúdo digital (Fonte: Macedo, 2010) 
Os leitores de tela: DOSVOX (Brasil) Virtual Vision (Brasil) Bridge (Canadá) JAWS (EUA), HAL (USA), Window-eyes (USA), e os navegadores: LYNX (EUA), Home Page Reader (EUA), Webspeak (EUA), são desenvolvidos para os deficientes visuais, por se comunicarem com o usuário por sintetizador de voz, para descrever a interface e os comandos de interação. Estes fazem leitura linear do conteúdo das páginas e permitem amplas configurações da verbalização (THATCHER, 2006).

A Figura 3 apresenta um mapa conceitual em que são ressaltados as características de acesso dos usuários com baixa visão. Nesta figura são apresentadas as principais barreiras encontradas no uso do computador assim como facilidades para seu acesso a esta ferramenta.

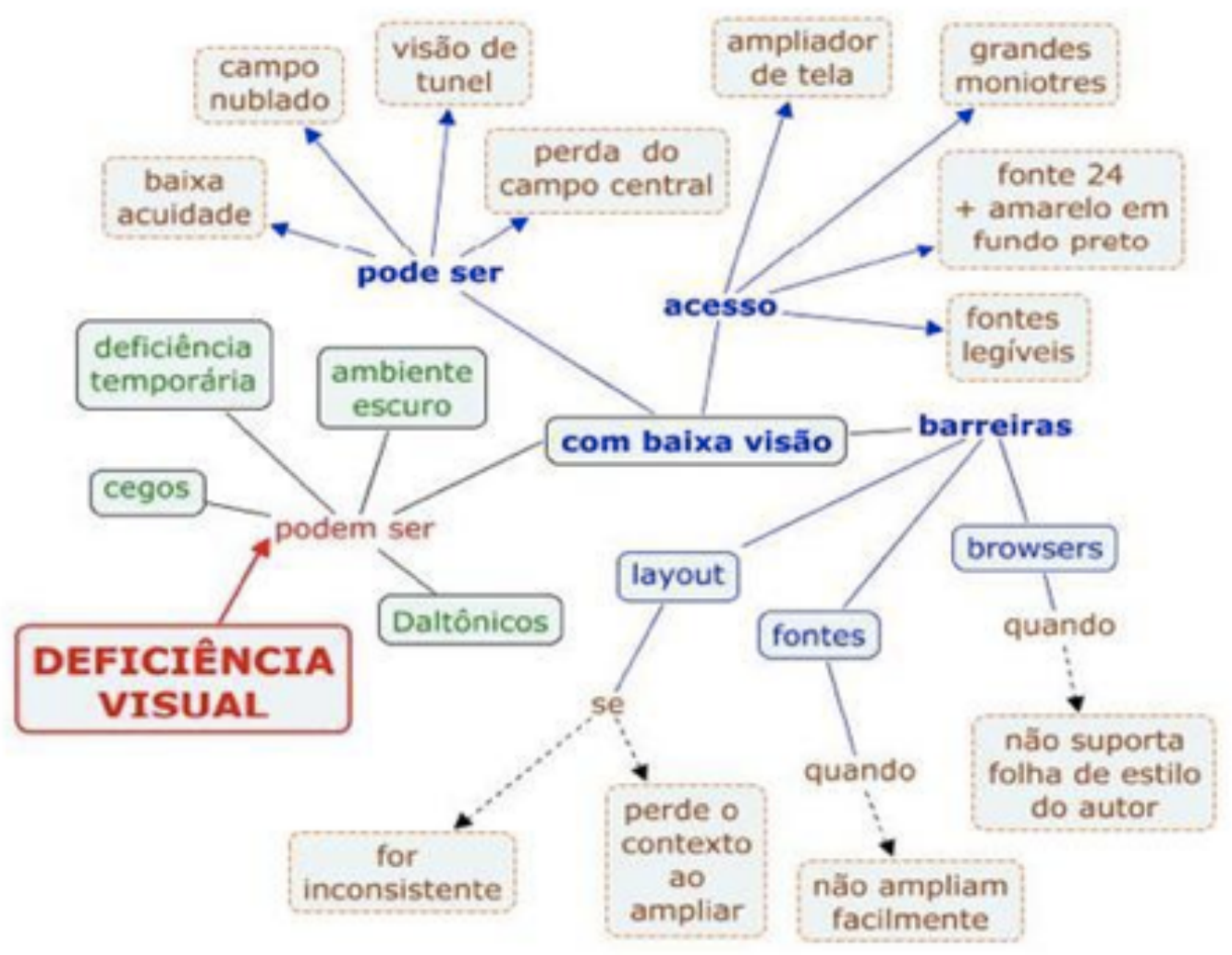

Figura 3 Mapa Conceitual das Características de Usuários com baixa visão (Fonte: Macedo, 2010)

Para estes usuários com visão reduzida vezes é possível apenas oferecer uma imagem de vídeo maior e mais limpa, ou apresentação em slides, com imagens simplificadas como alternativa para a narração em movimento (NIELSEN, 2000). O uso de textos em movimento deve ser cauteloso, pois podem causar epilepsia. Os sites devem oferecer alternativas de pausar os movimentos de scroll, ou balanço de animações. 
Os limites para os termos relacionados à pessoa com deficiência visual - cego e baixa visão - se dão por duas escalas oftamológicas, segundo Conde (2005): acuidade visual e campo visual. Mais do que aquilo que se enxerga a determinada distância, como relata o autor, acuidade visual é uma característica do olho de reconhecer dois pontos muito próximos; trata-se da clareza de visão dos detalhes. $\mathrm{O}$ campo visual é a amplitude, a abrangência do ângulo da visão em que os objetos são focalizados.

Essas medidas, contudo, pouco dizem sobre o real funcionamento visual de cada indivíduo, uma vez que duas pessoas com a mesma acuidade e com a mesma amplitude de campo visual podem apresentar níveis de funcionamento visual muito distintos (PEREIRA, 2008).

Com relação ao conceito de baixa visão, Sá, Campos e Silva (2007) destacam a complexidade do termo devido à variedade e à intensidade de comprometimentos das funções visuais. Essas funções englobam desde a simples percepção de luz até a redução da acuidade e do campo visual que interferem ou limitam a execução de tarefas e o desempenho geral. As pessoas com deficiência visual que apresentam baixa visão têm suas peculiaridades. Quase sempre precisam utilizar equipamentos ópticos, o que ocasiona dificuldade de relacionamento com os colegas que não possuem deficiência.

Para Amiralian (2004), a falta de identificação dessas pessoas como sujeitos de baixa visão e o deslocamento de seu déficit visual para outras áreas dificultam sua educação e a formação da personalidade. Às vezes são tratadas como pessoas cegas e às vezes são tratadas como pessoas sem deficiência, o que é prejudicial, uma vez que sua verdadeira capacidade visual pode ser ignorada.

Além da Baixa Visão e da Cegueira há outras deficiências ligadas à visão, por exemplo o daltonismo, que dificulta distinguir entre combinação ou pares de cores. Em geral, as pessoas com deficiência visual são as que possuem maior dificuldade em acessar os sites da internet, sobretudo pela natureza gráfica dessas páginas (DIAS, 2007).

Para desenvolver um ambiente virtual de ensino aprendizagem inclusivo foi necessário utilizar o mapa conceitual que descreva as características do público-alvo para então gerar o modelo de usuário genérico, base para a modelagem conceitual do ambiente.

Com os mapas conceituais que descrevem as características dos usuários foi possível criar um modelo de usuário genérico para o ambiente virtual de ensino aprendizagem acessível.

A princípio foram definidos os dados necessários ao desenvolvimento da base de dados do ambiente virtual de ensino aprendizagem acessível. Esses dados são: Identificador Único, Nome de Usuário, Senha, Nome, Sobrenome, Email, Curso, Série, Perfil.

A criação do Modelo de Usuário demandou o desenvolvimento de uma Classe que representasse os dados listados. Essa classe, posteriormente, será convertida em uma tabela de Banco de Dados. A Figura 4 apresenta a classe gerada. 


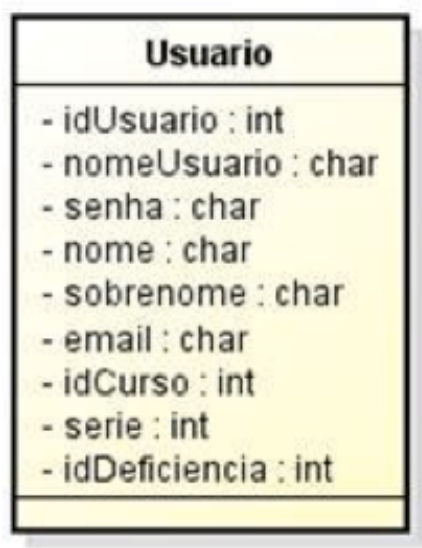

Figura 4 Classe representando o Modelo de Usuário (Fonte: os autores, 2010)

Este mesmo modelo, expresso em Classe, pode ser representado como um mapa conceitual, exibido na Figura 5.

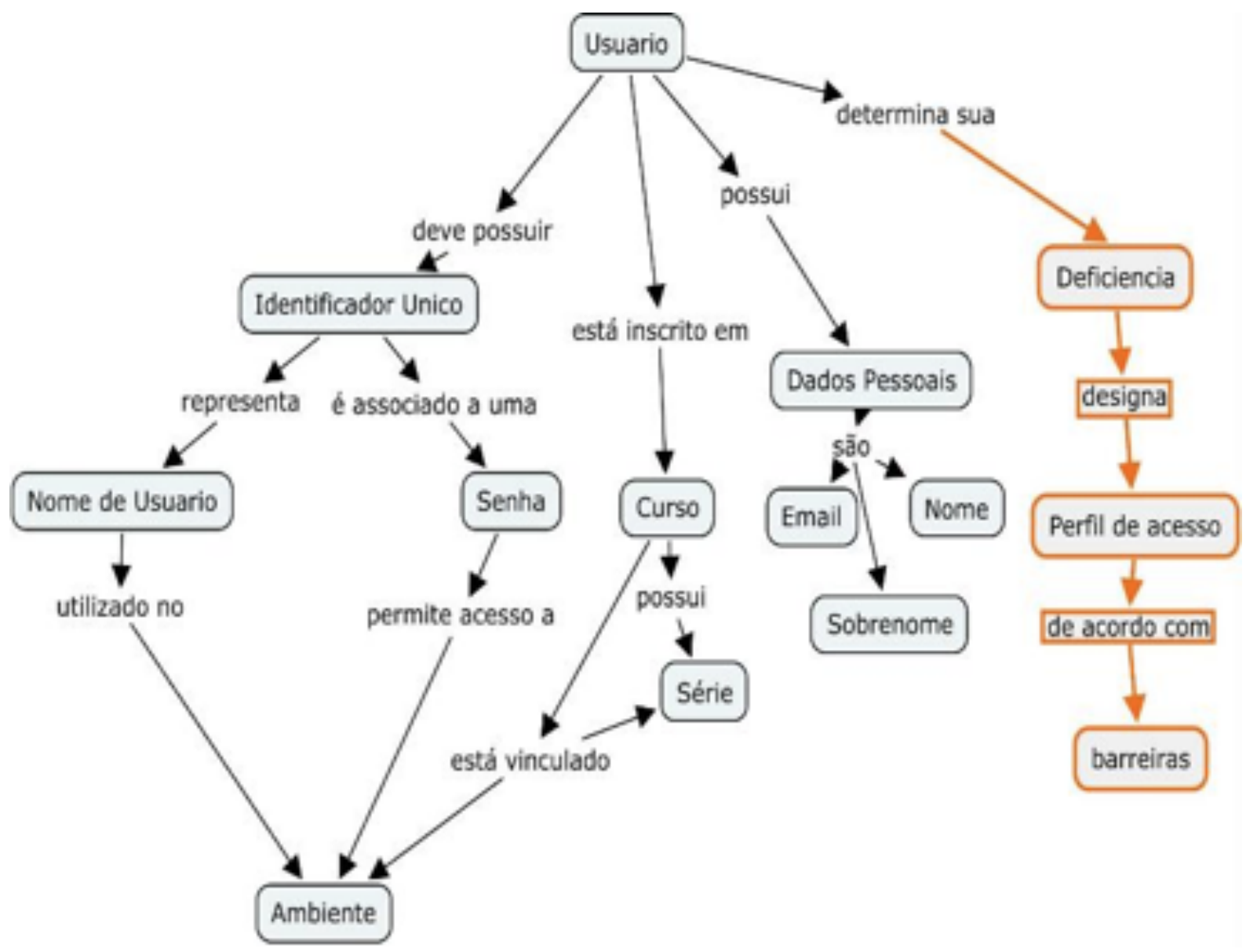

Figura 5 Modelo de Usuário Genérico representado por Mapa Conceitual (Fonte: os autores, 2010) 


\section{Resultados obtidos}

Existem diversos ambientes virtuais de aprendizagem que dão suporte ao Ensino à Distância, seja ele totalmente à distância ou semipresencial. Estes ambientes contam com arcabouço tecnológico para suprir atividades pedagógicas e administrativas que podem, então, apoiar o desenvolvimento de metodologias educacionais.

A pesquisa de Gabardo, Quevedo e Ulbricht (2010, P. 68) mapeou os ambientes virtuais de aprendizagem mais utilizados atualmente para cursos de EaD no Brasil e desenvolveu uma análise em que ficaram expressas as diferentes características e potencialidades desses ambientes. Além disso, a pesquisa buscou o aprofundamento dessa análise com vistas à identificação de características mais adequadas à acessibilidade.

Desta forma, foram selecionados oito AVAs mais citados nas fontes de pesquisa e utilizados pelas Instituições de Ensino Superior (IES) no Brasil. São eles: TelEduc, AulaNet, Amadeus, Eureka, Moodle, e-Proinfo, Learning Space e WebCT. Com objetivo de apurar suas diferenças, foram estabelecidos critérios de análise, a saber: distribuição, princípios pedagógicos, aprendizagem colaborativa, interatividade, multimídia, usabilidade e acessibilidade.

O estudo comparativo realizado mostrou que os ambientes virtuais de ensino a distância, apresentam lacunas em sua construção e/ou apresentação. Há disparidade em relação à oferta de ferramentas para o aprendizado colaborativo, assim como em relação à interatividade. Algumas plataformas apresentam mais recursos em uma e outra modalidade. Embora enfatizem a possibilidade de utilização de sistemas multimídia, seus sites não informam claramente sobre os recursos disponíveis. O quesito acessibilidade é o menos contemplado.

Diante do quadro exposto, como não foi encontrada nenhuma plataforma que atendesse a todas as demandas, principalmente ao requisito de acessibilidade optou-se pelo AVA Modular Object Oriented Distance Learning-Moodle que é uma plataforma livre e adotada por diversas universidades em todo o mundo. Seu desenvolvimento objetiva o gerenciamento do aprendizado e trabalho colaborativo em ambiente virtual. O Moodle possibilita a criação e gestão de cursos on-line, grupos de trabalho e comunidades de aprendizagem. Atualmente a comunidade envolvida com o Moodle consiste em 56.566 sites registrados, em 212 países, com 4.914.209 usuários e 46.151.117 professores, o que dá uma noção da abrangência e uso do ambiente (MOODLE, 2011). Outro fator que levou a escolha desta plataforma é sua importância para a Universidade Aberta do Brasil - UAB, projeto da CAPES-MEC, onde o Moodle é adotado.

Diante do exposto, o objetivo do projeto aqui relatado foi, apropriando-se dos mapas conceituais discutidos nas seções anteriores, alterar o funcionamento interno do ambiente virtual de aprendizagem de código aberto e gratuito Moodle 2.0 a fim de facilitar a criação de conteúdo acessível aos portadores de deficiências 
visuais e auditivas. Foi necessário realizar alterações no ambiente que contemplem interface intuitiva com inserção obrigatória de conteúdos alternativos e que tenham fraco impacto tanto ao código original do Moodle como a sua Base de Dados.

Para um aluno completamente cego é praticamente impossível a compreensão de um conceito que seja exibido em uma imagem na tela do computador. Sendo assim a solução proposta é baseada na ideia de que alunos deficientes devem ter o conteúdo multimídia apresentado de forma diferenciada (w3C, 2006), (IMS GLC, 2002). A fim de que o conteúdo de um elemento multimídia (imagens em movimento; tabelas; textos; imagens estáticas; gráficos e áudio), seja assimilado por uma pessoa com deficiências, este deve ser apresentado de uma forma alternativa. A Tabela 1 apresenta um resumo das recomendações do IMS aplicadas às diretrizes propostas.

Tabela 1 Recomendação do IMS aplicadas as diretrizes propostas.Fonte: Baseada no documento IMS-GLS - Princípios de Acessibilidade em Aprendizagem distribuída On-line. Elaborada por Claudia M. S. Macedo, 2010

\begin{tabular}{llll}
\hline Mídia & Importância de aplicação & $\begin{array}{l}\text { Métodos recomendados para } \\
\text { tornar acessível }\end{array}$ & Formatos alternativos \\
\hline Texto & $\begin{array}{l}\text { Quando corretamente formatado } \\
\text { e estruturado, pode ser o caminho } \\
\text { mais flexível para apresentaçwão } \\
\text { de conteúdo. }\end{array}$ & $\begin{array}{l}\text { Fornecer apresentação em } \\
\text { formato alternativo }\end{array}$ & $\begin{array}{l}\text { Apresentação visual na } \\
\text { tela. Tradução em fala por } \\
\text { sintetizadores. Informação tátil } \\
\text { em display Braille ou impressora } \\
\text { especial }\end{array}$ \\
\hline Áudio & $\begin{array}{l}\text { Pode ser um apelo adicional para } \\
\text { os indivíduos com impedimento } \\
\text { visual, disléxicos. }\end{array}$ & $\begin{array}{l}\text { Adicionar transcrição textual ou } \\
\text { Captions }\end{array}$ & Linguagem de sinais \\
\hline Imagem & $\begin{array}{l}\text { Pode fornecer uma informação } \\
\text { essencial }\end{array}$ & Fornecer identificação textual & $\begin{array}{l}\text { Texto Alternativo. Texto } \\
\text { Equivalente. Escalável. Opção } \\
\text { de cores. Descrição. }\end{array}$ \\
\hline Multimídia & Fornece apresentação multimodal. & $\begin{array}{l}\text { Apresentar opções de mídias, } \\
\text { para todas as mídias envolvidas. }\end{array}$ & $\begin{array}{l}\text { Legendas. Transcrição textual. } \\
\text { Áudiodescrição }\end{array}$ \\
\hline
\end{tabular}

O consórcio W3C (w3C, 2006) recomenda que se forneça texto equivalente associado a todo conteúdo não textual; imagens devem ter atributo alt-text, áudio e vídeos devem apresentar transcrição, e animações devem ser descritas em texto. O IMS GLC (2002) distingue os conteúdos equivalente e alternativo. Um conteúdo é definido como equivalente quando ele é idêntico a outro, porém fornecido em uma modalidade diferente, por exemplo, um texto disponível em áudio e o mesmo texto associado a um arquivo para impressão em Braille.

Já um conteúdo alternativo, é uma ampliação do conteúdo equivalente e é fornecido de forma diferente, porém com o mesmo objetivo final de aprendizagem. Na visão do W3C (w3C, 2006), o texto 
equivalente responde as mesmas funções e cobre a mesma informação que o conteúdo não textual.

O ambiente deve levar o conteudista à inserção obrigatória de formas alternativas para cada um dos conceitos apresentados por meio das diferentes mídias. Propõe-se, consequentemente, que as deficiências do usuário sejam armazenadas em banco de dados para que, no momento de construção da página do curso que lhe é apresentado, o ambiente, no servidor, seja capaz de anexar dados relativos às deficiências para que então, no cliente, possa ser decidida a maneira de apresentação do conteúdo multimídia. A Figura 6 ilustra o conceito.

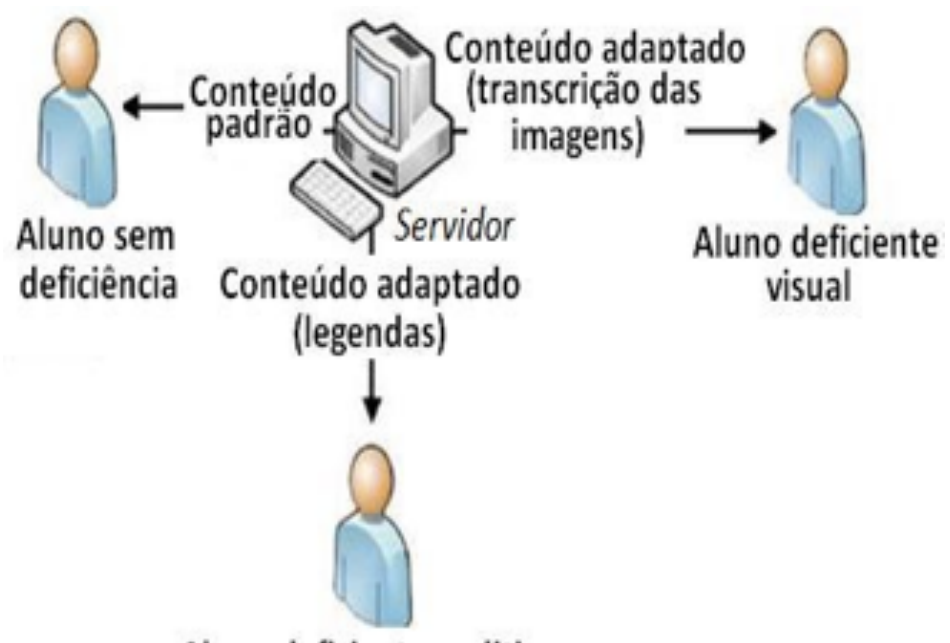

Aluno deficiente auditivo

Figura 6 Adequação do conteúdo ao aluno e definição da deficiência pelo ambiente. (Fonte: os autores, 2010)

Além das alterações propostas no ambiente, é preciso padronizar o uso de determinadas ferramentas, como, por exemplo, o editor de texto a ser utilizado pelo usuário cego. O editor de textos a ser instalado, configurado e alterado, nesta pesquisa, é o TinyMCE, escolhido por possuir código aberto, livre, e ter disponibilidade de Plug-ins. O funcionamento do editor de textos será alterado para obrigar a inserção de conteúdos alternativos das mídias, como imagens e vídeos.

A questão da adequação do conteúdo do aluno dada a definição de seu perfil pelo ambiente foi tratada no mapa conceitual que representa o Modelo de Usuário Genérico. A Figura 7 exibe a ramificação do mapa conceitual que apresenta as considerações sobre a deficiência do usuário e, portanto seu perfil de acesso de acordo com as barreiras que o ambiente deverá transpor na adaptação do conteúdo. 


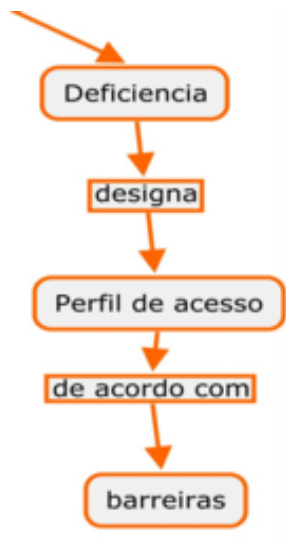

Figura 7 Mapa Conceitual do Modelo de Usuário. (Fonte: os autores, 2010)

Outra questão considerada relaciona-se ao idioma da plataforma Moodle, já que a versão 2.0 ainda não foi inteiramente traduzida ao português brasileiro. A tradução foi feita, alterando-se o código fonte do Moodle e do editor de textos TinyMCE.As demais alterações executadas no ambinte Moodle, a fim de prover acessibilidade, são apresentadas nos itens que seguem:

a. Cadastro e Edição de Alunos: O sistema Moodle já possui informações sobre a utilização de leitura de telas. O nome deste campo foi alterado para "Deficiente Visual". O conteúdo padrão destes campos deve ser "Não Marcado". A interface de criação e edição de usuários alterada é ilustrada na Figura 8. Esta alteração foi implementada da seguinte forma: criação da categoria de campos customizados "Deficiências" e dois campos obrigatórios, "Visual" e "Auditiva"; ocultamento da opção "Leitor de tela".

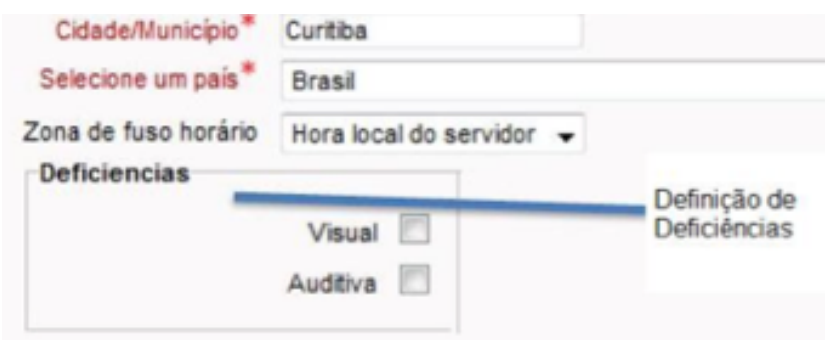

Figura 8 Alteração gerada no Moodle. (Fonte: os autores, 2010)

b. Inserção de Imagens no Conteúdo dos Cursos: O conteúdo padrão de um curso é composto por paginas HTML que contém textos e elementos HTML, tais como imagens, tabelas, vídeos e sons. Para as pessoas com deficiência visual a forma de apresentação, destes conteúdos, deve ser diferente. Como solução alterou-se o funcionamento de inserção de conteúdo HTML. O sistema Moodle fornece um editor WYSIWYG (What You See Is What You Get), que permite a fácil entrada 
de dados formatados em HTML sem que o conteudista seja obrigado a conhecer a linguagem. Nas telas de inserção de conteúdo multimídia, propõe-se a criação de um campo customizado e obrigatório, em que o conteudista deve inserir o texto alternativo. A caixa de diálogo de inserção de imagens terá seu comportamento alterado, conforme o fluxo de dados apresentado na Figura 9.

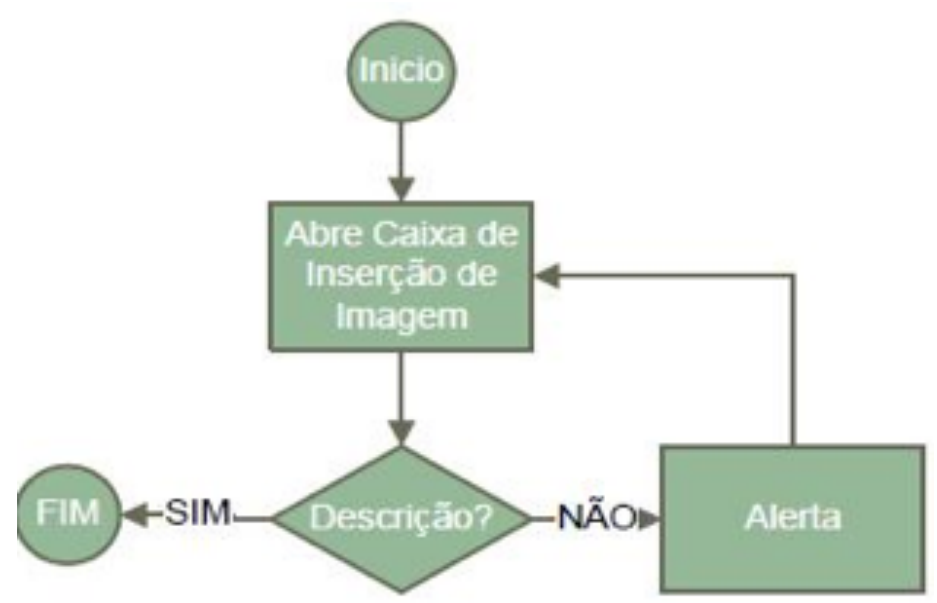

Figura 9 Fluxograma de inserção de imagens (Fonte: os autores, 2010)

O texto alternativo é obrigatório, e caso ele não seja preenchido, o conteudista não poderá inserir a imagem, e receberá uma mensagem solicitando o texto e mostrando um exemplo de texto alternativo. Esta ação remete à modelagem apresentada no mapa conceitual que descreve a matriz do processo de ensino aprendizagem.

A Figura 10 apresenta a área do mapa conceitual que define tal situação e a Figura 11 mostra a tela inserida no ambiente Moodle para garantir que o AVA seja inclusivo.

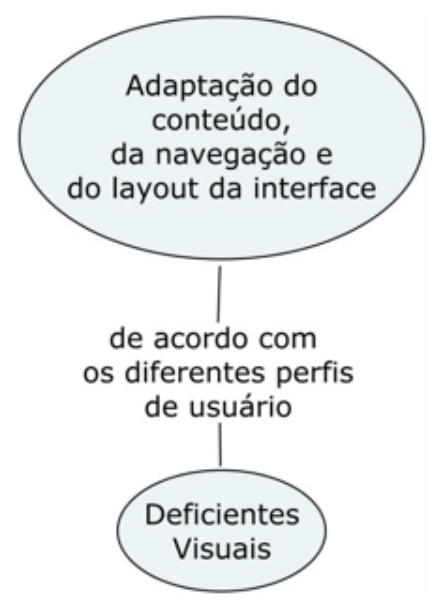

Figura 10 Mapa conceitual. (Fonte: os autores, 2010) 


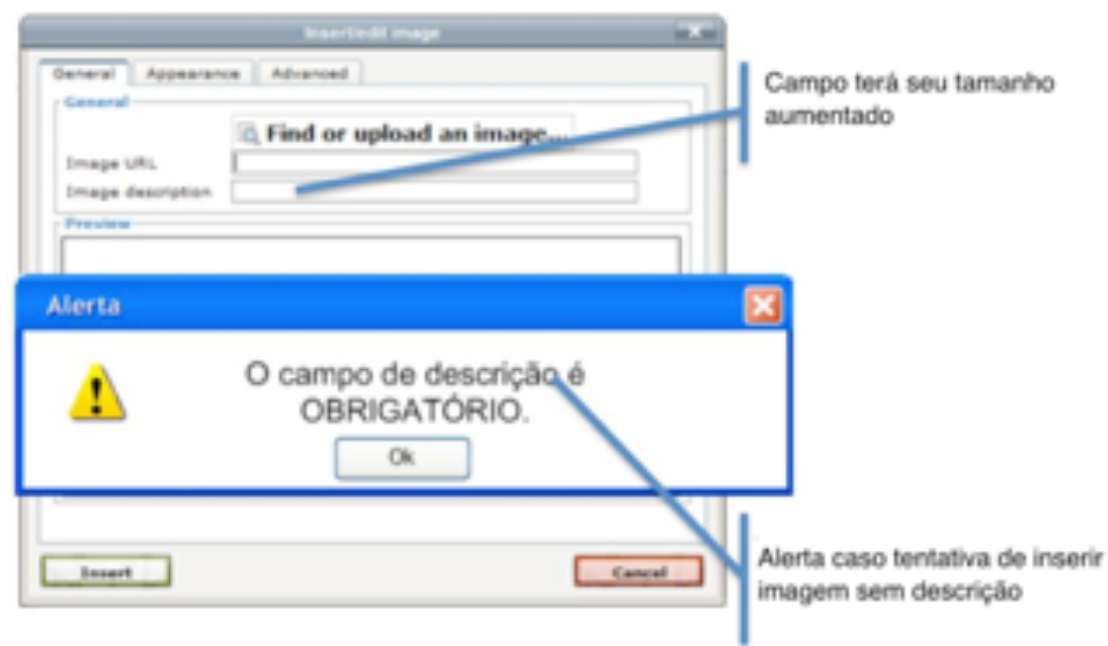

Figura 11 Janela de inserção de imagens (Fonte: os autores, 2010)

c. Inserção de Tabelas no Conteúdo dos Cursos: A caixa de diálogo de inserção de tabelas teve seu comportamento alterado para tornar obrigatório o texto alternativo e caso ele não seja preenchido, o conteudista não pode inserir a tabela. Os dados do texto alternativo serão armazenados dentro do atributo summary da marca table.

d. Inserção de Vídeo: A caixa de diálogo de inserção de vídeos tem o comportamento semelhante ao da inserção de tabela. O conteúdista deverá inserir algum texto alternativo, ou a descrição, ou a transcrição, do vídeo. Caso ao menos um deles não seja preenchido, o conteudista não poderá inserir o arquivo de vídeo.

e. Exibição do Conteúdo em HTML: O módulo de construção de páginas HTML do ambiente Moodle foi alterado para suportar a criação de diferentes páginas em função do perfil do aluno. Para os alunos sem deficiências, as páginas serão exibidas com seus conteúdos originais. Aos alunos com deficiência, as mídias serão exibidas de acordo com as normas da tabela 2 .

Tabela 2 Conteúdos alternativos exibidos aos deficientes

(Fonte: os autores, 2010)

\begin{tabular}{ll}
\hline Elemento & Deficiência Visual \\
\hline Imagem & Descrição textual. \\
\hline Tabela & Descrição textual. \\
\hline Som & Original. \\
\hline Vídeo & Transcrição. \\
\hline
\end{tabular}


f. Exibição Normal: A um aluno sem deficiências, a exibição das páginas será normal, sem nenhuma alteração (Figura 12).

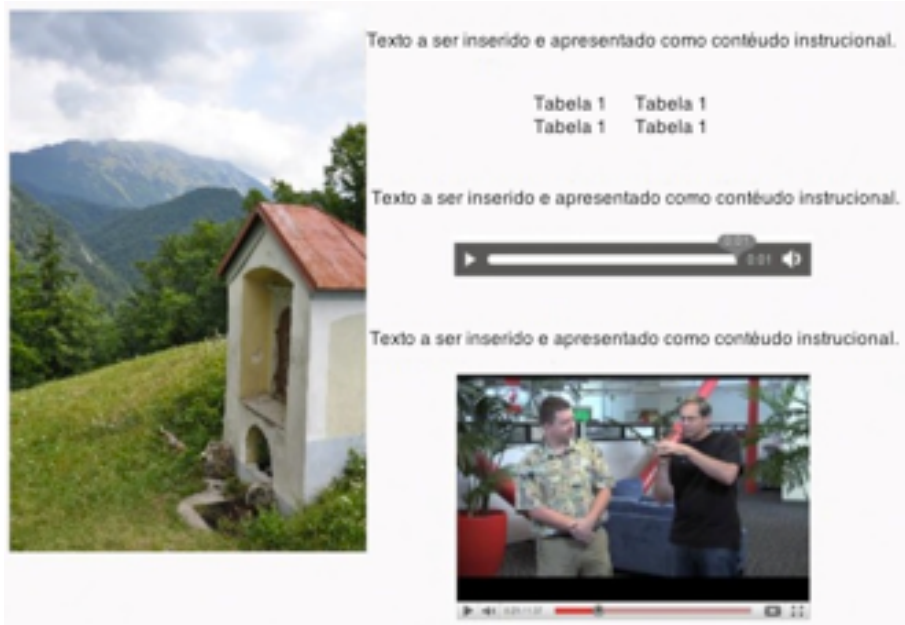

Figura 12 Exibição normal (Fonte: os autores, 2010)

g. Exibição a um usuário com deficiência visual: A exibição das páginas a um aluno deficiente visual terá os conteúdos gráficos alterados, como ilustra a Figura 13.

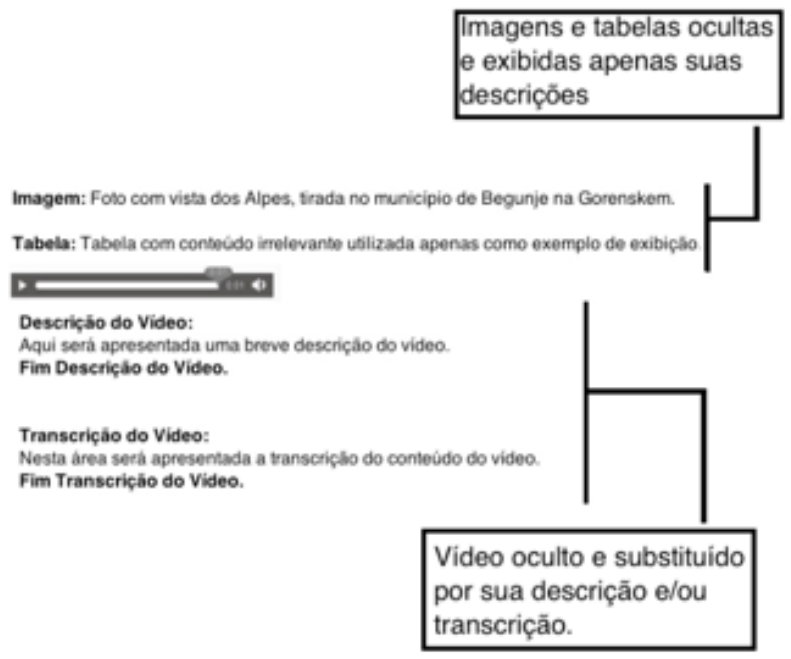

Figura 13 Exibição a um deficiente visual (Fonte: os autores, 2010)

Além das páginas, outros elementos do Moodle tiveram também seu conteúdo alterado da mesma forma. É importante ressaltar que a maior parte dos elementos e recursos do ambiente Moodle possuem uma introdução ou descrição, e este campo é tratado na hora de exibir 
o conteúdo ao usuário. Os recursos do ambiente Moodle considerados nesta pesquisa são as páginas HTML. As atividades consideradas foram: fórum e wiki. Recursos e atividades que não possuem elementos multimídia não precisam ser tratados.

É preciso salientar que, para este primeiro estudo, existe a limitação de acessibilidade com relação a alguns documentos que possam ser anexados no Moodle (Word, PPT e outros), uma vez que a arquitetura proposta considera apenas os conteúdos inseridos via interface Moodle, sem considerar arquivos anexados.

Como esta limitação é intrínseca ao formato de tais arquivos, e o único modo de torná-los acessíveis por meio da exibição de conteúdo alternativo será a sua conversão para o formato HTML. A melhor maneira de fazer esta conversão foi no próprio programa de origem, o que deve ser considerado pelo autor do curso.

\section{Considerações finais}

A modelagem de aplicações hipermídia pode ser tratada com diversos métodos, entre eles os que são orientados a objeto ou os diagramas entidade-relacionamento. Como resultado da pesquisa foram gerados os mapas conceituais do domínio, do modelo de usuário e também da matriz do processo de ensino-aprendizagem.

Esta pesquisa apresentou o uso de mapas conceituais para a modelagem de aplicações hipermídia adaptativas. Este tipo de representação foi escolhido por transpor os paradigmas de orientação a objeto ou entidade-relacionamento e trazer informações mais claras, organizadas e conceituais sobre as características da aplicação hipermídia.

Desta forma, foi possível observar a estrutura hierárquica e as relações mais importantes entre os conceitos do domínio, bem como entre os conceitos que representam as características dos usuários. Foi possível observar que os mapas se mostraram eficientes, já que são uma forma fácil e direta de interpretação dos conceitos envolvidos no desenvolvimento da hipermídia.

A criação de mapas distintos para descrever as características de públicos específicos, como as pessoas com deficiência visual e auditiva, apoiou o desenvolvimento do Modelo de Usuário, que também foi retratado aqui por meio de mapa conceitual.

Por permitirem o estabelecimento de relacionamentos entre os conceitos que apresentam, os mapas conceituais se tornam também uma ferramenta muito útil na elaboração de um ambiente hipermediático, quando este prevê a apresentação do conteúdo sob diferentes narrativas.

Eles facilitam a visualização das relações estabelecidas entre essas diferentes maneiras de apresentar um conteúdo, em sintonia com o design da informação, que prima pela forma visual e detalhada de se adquirir determinada informação. 
É interessante salientar que os próximos passos do desenvolvimento do ambiente virtual de ensino aprendizagem acessível incluirão a utilização de mapas conceituais como base para sua implementação. Como desdobramentos desta pesquisa, o ambiente deve ser validado junto ao público alvo, para que os resultados obtidos possam dar condições a ajustes nos modelos e nas interfaces propostas.

\section{Referências:}

Amaral, M. (1999). Modelo RHA - Retroalimentação em Hipermídia Adaptativa. Tese de Doutorado. Universidade Federal de Santa Catarina, PPGEGC, 2008. Souza.

Amiralian, M. L. T. M. (2003). O psicodiagnóstico do cego congênito aspecto cognitivos. Dissertação (Mestrado em Psicologia) Instituto de Psicologia, Universidade de São Paulo, São Paulo.

AUSUBEL, D. P. (1963). The psychology of meaningful verbal learning. Nova York: Grune and Stratton. (1968). Educational psychology: a cognitive view. Nova York: Holt Rinehart and Winston.

AUSUBEL, D. P. N.; JOSEPH D.; HANESIAN, H. (1978). Educational psychology: a cognitive view. 2 ed., Nova York: Holt Rinehart and Winston.

BURgstahler, S. (2000). Access to Internet-Based Instruction for People with Disabilities. Hershey, PA, USA: Idea Group Inc.

CONDE, A. J. M. (2011). Definindo a cegueira e a deficiência visual. Disponível em http://www.laboratoriorigor.com.br/ler_noticia,4.html. Acessado em 02 fev 2011.

DIAS, C. (2007). Usabilidade na Web: Criando portais mais acessíveis. Rio de Janeiro: Alta Books, p. 296.

GowIN, D. B. (1981). Educating. Ithaca, NY, Cornell University Press.

IMS GLC. (2002). IMS Guidelines for Developing Accessible Learning Applications V.1 White Paper. IMS Global Learning Consortium Inc., 27 junho 2002.

KосH, N. (2001). Software Engineering for Adaptive Hypermedia Systems: Reference Model, Modeling Techniques and Development Process. Tese de doutorado. LÁzAro, R. C. G. (2010). Deficiência Visual. Instituto Benhamin Constant. Disponível em WWW.ibc.gov.br, acessado em 24 out 2010.

MACEDO, C. M. S. (2010). Diretrizes para criação de objetos de aprendizagem acessíveis. Tese. Florianópolis, SC.

MOODLE. (2011). Estatísticas Moodle. Disponível em: <http://moodle.org/stats>. Acesso em: 28 set. 2011.

MOREIRA, M. A. (1997). Mapas Conceituais e Aprendizagem Significativa, UFRGS, Porto Alegre.

MOREIRA, M. A.; BUCHWEITZ, B. (1993). Novas estratégias de ensino e aprendizagem: os mapas conceituais e o Vê epistemológico. Lisboa: Plátano Edições Técnicas. NIELSEN, J. (2000). Designing Web Usability - The Practice of Simplicity. USA: New REaders Publishing. 
NOvaK, J. D. (1998). Learning, Creating, and Using Knowledge: Concept Maps As Facilitative Tools in Schools and Corporations. New York: Lawrence Erlbaum Assoc. (1981). Uma teoria de educação. São Paulo: Pioneira.

NOVAK, J. D.; GOWIN, D. B. (1996). Aprender a aprender. Lisboa: Plátano Edições Técnicas.

NOVAK, J. D.; CAÑAS, J. A. (2004). Building on New Constructivist Ideas and CmapTools to Create a New Model for Education. Institute for Human and Machine.

Pereira, A. T. C. (2008). Processo de Projeto de Hipermídia para Aprendizagem do Curso Letras/LIBRAS. Congresso Nacional de Hipermídia para Aprendizagem - $3^{\underline{0}}$ CONAHPA, 2008, São Paulo: Anhembi Morumbi.

QUEVEDO, S.; ULBRICHT, V. R. (2010). Estudo comparativo das plataformas de ensino aprendizagem. In: 16º CONGRESSO INTERNACIONAL ABED DE EDUCAÇÃO A DISTÂNCIA, 2010, Foz do Iguaçu. Anais do 16ํㅜ Congresso internacional ABED de Educação a Distância. São Paulo : ABED. p. 1-8.

ROBINSON, D. H.; KIEWRA, K. A. (1995). Visual Argument: Graphic Organizers Are Superior to Outlines in Improving Learning From Text, American Psychological Association.

SÁ, E. D.; CAMPOS, I. M.; SILVA, M. B.C. (2007). Atendimento Educacional Especializado em Deficiência Visual. Brasília: Formação continuada a distância de professores para o atendimento educacional especializado.

SAntos, G. H. O. (2006). Diferentes Modos de Produção de Significados de Deficientes Visuais para Geometria. In: SANTOS, Glauco Henrique de Oliveira Dissertação de Mestrado: Uma Leitura da Produção de Significados de Pessoas com Deficiência Visual para a Geometria. Juiz de Fora: Centro de Ensino Superior de Juiz de Fora. p. 03-05.

SOUZA, R. R. (1999). Usando Mapas Conceituais na Educação Informatizada Rumo a um Aprendizado Significativo, EDUTEC, São Paulo.

TAROUCO, L. M. R. ET AL. (2004). Objetos de Aprendizagem para M-learning. Florianópolis: SUCESU - Congresso Nacional de Tecnologia da Informação na Construção.

THATCHER, J. (2006). Assistive Technology: Screen Readers and Browsers. In: HOLZSCHLAG, M. E. Web Accessibility - Web Standards and Regulatory Compliance. New York: Springer-Verlag New York, Inc.

w3C. (2006). Why Standards Harmonization is Essential to Web Accessibility. W3CWAI, 17 março 2006.

\section{Sobre as autoras}

\section{Marília Abrahão Amaral}

<mariliaa@utfpr.edu.br>

Doutora em Engenharia e Gestão do Conhecimento, Universidade Tecnológica Federal do Paraná - Programa de Pós-graduação em Tecnologia (PPGTE). 


\section{Silvia Regina Pochmann de Quevedo}

$<$ silviareginaquevedo@hotmail.com>

Doutora em Engenharia e Gestão do Conhecimento. Pós-doutoranda do Programa de Pós Graduação em EGC (PPEGC) - Universidade Federal de Santa Catarina (UFSC).

Artigo recebido em 8 out. 2013, aprovado em 12 dez. 2013. 